\title{
GESTÃO PÚBLICA E SUSTENTABILIDADE: DESAFIOS, AÇÕES E POSSIBILIDADES
}

Gustavo Antiqueira Goes ${ }^{1}$

\section{Angélica Gois Morales ${ }^{2}$}

RESUMO: A gestão pública, pela complexidade que exerce, pode ser olhada como uma área dentro da administração cheia de problemas. Dentre essa complexidade de gestão, deve também ser a principal percussora para a iniciativa de ações de sustentabilidade e de desenvolvimento que estimule a população a adotar práticas ambientais. Portanto, esse o artigo teve como objetivo conceituar gestão pública e sustentabilidade, a fim de uma reflexão da aproximação entre esses dois conceitos que devem estar amplamente interligados, e dos desafios e ações educativas na gestão pública em atuar no caminho da sustentabilidade. Tal reflexão nos permite verificar a diferença da tendência conceitual entre sustentabilidade e desenvolvimento sustentável, bem como compreender que a gestão pública é uma esfera de grande complexidade e que, em primeiro momento é necessário olhar as dificuldades e desafios de cada município para serem superados e alcançados possíveis soluções com base em práticas mais sustentáveis orientado pela educação.

Palavras-chave: Gestão pública, Sustentabilidade, Práticas Educativas.

\section{INTRODUÇÃO}

\footnotetext{
${ }^{1}$ Especialista em Gestão Empresarial pela UNITOLEDO (2011), graduado em Enfermagem pela ESEFAP (2008), e graduando em Administração pela UNESP campus de Tupã-SP. gustavogoes26@gmail.com

${ }^{2}$ Doutora em Meio Ambiente e Desenvolvimento (UFPR-PR), mestra em Educação Ambiental (FURG-RS). Licenciada em Ciências Biológicas (UNESP). Docente do curso de Administração da Unesp, campus de Tupã-SP. angelica@tupa.unesp.br
} 
Com as profundas mudanças sociais e econômicas que são geradas pelas políticas locais, nacionais e mundiais, as cidades requerem novas formas para entender, e desenvolver práticas de sustentabilidade.

Com o passar dos anos, notou-se que para o desenvolvimento de ações de sustentabilidade sejam efetivamente inseridas, elas teriam que ser trabalhadas em níveis grupais cada vez menores, a fim de que as cidades, e as sociedades espalhadas ao redor do planeta possam ter orientação para prática diária. O grande desafio para a administração pública está em desenvolver modelos de gestão, que alinhem suas missões e objetivos às responsabilidades em querer preservar o meio ambiente (MUNCK; SOUZA, 2009).

Idealizando a liderança pública, e mediante os desafios enfrentados para administrar uma cidade inteira, este artigo tem como objetivo conceituar gestão pública e sustentabilidade, a fim uma reflexão da aproximação entre esses dois conceitos que devem estar amplamente interligados. Nesse encaminhamento torna-se importante: a) esclarecer o entendimento conceitual, que muitas vezes é apontado como sinônimo, mas que possui sentidos diferentes, o que traz a importância de uma abordagem conceitual e histórica, a partir da diversidade de sentidos e ações envolvidos nesse debate; b) refletir sobre os desafios e as ações educativas na gestão pública em atuar no caminho da sustentabilidade.

Esse artigo é fruto de um ensaio teórico, a partir de pesquisas bibliográficas no qual busca por meio de fontes primárias e secundárias, compreender, analisar de forma aprofundada os aspectos conceituais da sustentabilidade, desenvolvimento sustentável e gestão pública já que são temas que apresentam bastante material produzido, mas pouco articulado.

\section{CONTEXTUALIZAÇÃO DA GESTÃO PÚBLICA}

A gestão pública é de extrema importância para sua população, pois é ela quem define os caminhos a seguir para poder fazer com o que município cresça e se desenvolva. O modelo de gestão pública foi inspirado na gestão de empresas privadas, 
consolidando-se na diferença de que se é defendido o interesse público em primeiro plano. Com isso primeiramente é dado prioridade às necessidades da população e seus interesses para que sejam tomadas decisões (COUTINHO, 2000).

Segundo Lima (2007), o termo gestão pública pode ser conceituado como atos administrativos sendo classificados por processos como: planejamento, programação orçamentaria, execução, controle e avaliação das politicas que vise à concretização de politicas públicas, diretas ou indiretamente, por organizações públicas ou privadas.

Já segundo a autora Neves (2002, p. 21),

[..] durante muito tempo, o conceito de gestão não foi considerado aplicável aos dirigentes da administração pública, considerando que o seu papel era administrar, de acordo com regras pré-estabelecidas, os recursos afectos aos seus serviços, garantindo assim, o comprimento de atribuições e o exercício de competências igualmente pré-definidas em diploma orgânico.

Ainda que, analisando as ideias da autora Neves (2002), os administradores públicos de antigamente, apenas garantiam o cumprimento de ordens das quais estabeleciam, mas não analisavam em si, os munícipios como empresas que deveriam se desenvolver para o crescimento, e assim, beneficiar seus colaboradores que aqui seriam a população. A gestão pública tem centrado seus funcionamentos e trabalhos numa forma de estabilidade, priorizando o pensamento apenas de que suas competências são que as repartições públicas, aqui focando as prefeituras, devem estar ou tentar manter estável alguns pilares como os recursos humanos, de materiais e principalmente o financeiro. Porém a realidade é contraditória, pois quem gerencia um serviço é frequentemente atacado por diferentes tipos de solicitações, preferencialmente de natureza politica, e de cidadãos que esperam a resolução de problemas. Quem gere um serviço público vê-se, por outro lado pressionado em administrar vários e diferentes tipos de recursos, que na grande parte das vezes pode já conter vários problemas de outras gestões.

Para Lima (2007), a gestão pública é responsável pelo desenvolvimento urbano e econômico de uma cidade. Mas a gestão deve se atentar para aspectos de todos os fatos que podem acontecer numa sociedade. A gestão pública deve ter um posicionamento de uma missão para ser cumprida, que no caso é o desenvolvimento da cidade em beneficio do povo que nela habita.

A gestão pública enfrenta muito mais do que podemos imaginar. Conforme Dowbor (2011), 
o ser humano vem de longa trajetória e tradição cultural de que a natureza é de certa maneira infinita, e o objetivo era dela conseguir extrair o máximo possível. A empresa que conseguisse tirar mais petróleo, derrubar mais matas, pescar mais peixe ou extrair mais água, tirando maior vantagem, mostrava os resultados como prova de sucesso, de competência.

Diante da trajetória urbana, a forma de apropriação e percepção da natureza, tem passado por mudanças culturais, e como reforçou Dowbor (2011), antes quanto mais se extraia da natureza, melhor era vista tal empresa, sendo sinônimo de sucesso, e hoje, já se busca um gerenciamento mais racional, de forma que precise devastar menos, assegurando a conservação e preservação ambiental.

As cidades, como organismos totalmente complexos e, com vários níveis de atuação, apresentam inúmeras dificuldades, entre elas, aquelas voltadas para questões sócio ambientais. Olhando para essa questão a gestão pública deve desempenhar um papel relevante voltado para todos os segmentos da sociedade e buscar a reflexão e solução de soluções que permeiem a sustentabilidade. Sabe-se que há grandes desafios para se conduzir um município, e cada vez mais, a questão socioambiental é cobrada pela sociedade, e na prática, existem inúmeras outras questões a serem analisadas por uma gestão pública, como saúde, obras, agricultura, esporte, entre outras

O meio ambiente devido aos seus grandes impactos, têm merecido muitas preocupações por parte de todos e, exige uma atenção maior ainda por parte dos gestores públicos, principalmente porque os ambientes urbanos têm concentrado cada vez mais populações, especialmente no Brasil (REZENDE; OLIVEIRA, 2004). Sendo assim, as estratégias de desenvolvimento urbano acabam passando pela discussão de um modelo de desenvolvimento que agregue a promoção econômica junto com a preservação e conservação ambiental e a participação social.

\section{SUSTENTABILIDADE E DESENVOLVIMENTO SUSTENTÁVEL: 0 MESMO DISCURSO?}

Com a percepção de que alguns de nossos recursos naturais estão se tornando escassos, em relação ao meio ambiente e práticas não tão sustentáveis começamos a repensar nossas ações. Nossas perspectivas para o futuro são de dar continuidade em 
nossa existência de modo que consigamos produzir com o mínimo possível e ainda saibamos administrar de modo eficiente todos os recursos naturais. Soluções de como o uso da água mais eficiente, reduzindo desperdícios e tratando efluentes urbanos de modo que possamos reutilizá-lo por muito tempo, tem se mostrado criterioso quando ficamos, por exemplo, com a falta dela em nossas "torneiras" (HOGAN, 2005).

Tomando como base de que a maior parte da população brasileira vive em cidades com sociedades organizadas, observa-se uma grande degradação das condições de vida, em contrapartida gerando uma crise ambiental. O conceito de sustentabilidade é um conceito polissêmico, mas que aparece como um termo bastante expressivo no debate socioambiental. O conceito em si é um termo definido como a capacidade de um sistema manter sua produção diante de adversidades segundo Herrero (2000, apud MUNCK; SOUZA, 2009).

Nota-se que as reflexões atuais diante da valorização da natureza e sua relação com a sociedade, remetem a um pensar e repensar o desenvolvimento socioeconômico e a relação complexa entre sociedade e natureza (MORALES, 2012). Essas reflexões datam desde 1950 em que há a discussão "(...) das desigualdades entre países ricos e pobres e que se dá abertura à elaboração das estratégias de desenvolvimento" (MORALES, 2012, p.62). Mas, foi a partir da década de 1970, com a Primeira Conferência Mundial sobre o Homem e Meio Ambiente que ocorreu em Estocolmo, realizado no ano de 1972, que decidem criar o Programa das Nações Unidas para o Meio Ambiente (PNUMA) que contribuíram com esse embate.

Em 1973 é trazido por Maurice Strong o termo ecodesenvolvimento, divulgado principalmente pelo economista francês Ignacy Sachs, com a ideia de um desenvolvimento endógeno e dependente de suas próprias forças, e ainda, desejável sob os pontos de vista social, econômico e ecológico e dado ênfase a autonomia local, ligado a uma postura solidária. (MORALES, 2012).

No final da década de 1980 que a expressão "desenvolvimento sustentável se fortaleceu, principalmente pela formação da Comissão Mundial sobre Meio Ambiente e Desenvolvimento, cujo tema central era Uma agenda global para a mudança”, cujo fruto é o relatório Brundtland conhecido como Nosso Futuro comum, no qual traz a proposta do termo sustentável como estratégia de desenvolvimento (MORALES, 2012; BOFF, 2012). É nesse relatório que traz a definição tão conhecida do desenvolvimento sustentável 
como "aquele que procura satisfazer as necessidades da geração atual sem comprometer as necessidades das gerações futuras”. E ainda traz que "(...) tanto a tecnologia quanto à organização social podem ser geridas e aprimoradas a fim de proporcionar uma nova era de crescimento econômico." (COMISSÃO MUNDIAL SOBRE MEIO AMBIENTE E DESENVOLVIMENTO, 1991, p.9). Nesse enfoque dado pela Comissão, pode-se verificar sentido um tanto diferente do enfoque do ecodesenvolvimento, pois como Luz (2001) aponta, o desenvolvimento sustentável condiciona a mudança a um tipo de desenvolvimento menos agressivo, mas ainda pautados exclusivamente nos aspectos econômicos. Já o ecodesenvolvimento traz um repensar a relação sociedade e natureza. Assim, o que se observa foi um esvaziamento do conteúdo e princípios do ecodesenvolvimento pela Comissão Brundtland, mesmo sendo apoiada por essas ideias.

Em 1992, com o evento Conferência das Nações Unidas sobre Meio Ambiente e Desenvolvimento no Rio de Janeiro, o desenvolvimento sustentável foi bastante discutido e apoiado pelos governos nacionais e internacionais, sendo produzido o material Agenda 21 - como um plano de ação que busca ter ações globais. Nota-se que a globalização está diretamente ligada as tendências da modernização, que por sua vez, é o estágio contemporâneo da modernidade.

Já a sustentabilidade, ao pensamento de Sachs (1994), é enfatizada, tanto no ecodesenvolvimento, quanto no desenvolvimento sustentável, o foco deve estar na articulação entre os objetivos econômicos, sociais e ambientais, com atenção a outras variáveis e/ou dimensões que compõem a sustentabilidade, como a política, a cultural, a espacial, entre outras. Porém, nota-se que o discurso do desenvolvimento sustentável é marcado por um contexto bastante pragmático e instrumental, sendo proposto ou interpretado como

[...] um ideal a ser atingido ou então como um qualificativo de um processo de produção ou de um produto, feito pretensamente dentro de critérios de sustentabilidade, o que, na maioria dos casos, não corresponde a verdade. Geralmente, entende-se a sustentabilidade de uma empresa se ela consegue se manter e ainda crescer, sem analisar os custos sociais e ambientais que ela causa (BOFF, 2012, p. 36-37).

Nesse sentido, mesmo que o termo sustentabilidade está conectado com o termo desenvolvimento sustentável atualmente, chama a atenção que tendo sentidos um pouco diferentes. O autor Cabrera (2009) retrata que Sustentabilidade, 
[...] trata-se de um conceito sistêmico, ou seja, ele correlaciona e integra de forma organizada os aspectos econômicos, sociais, culturais e ambientais da sociedade. A palavra-chave é continuidade - como essas vertentes podem se manter em equilíbrio ao longo do tempo.

Pois bem, a diferença entre sustentabilidade e desenvolvimento sustentável para que possamos ter uma melhor compreensão, é de que sustentabilidade é um tripé que dever ser mantido de forma articulada e integrada pelos pilares, econômicos, sociais e ambientais enquanto o desenvolvimento sustentável é o que nos leva a olharmos mais a frente, dentro do desenvolvimento e crescimento vistas ao o futuro e construirmos soluções para que nosso planeta e nossos recursos se mantenham estáveis para as próximas "vidas".

Ainda que, segundo o autor Jacobi (2003), analisando que moramos em sociedade, essa percepção de sustentabilidade deve ser analisada regionalmente, ou definida por cidades (localmente) podendo assim fazer repensar e desenvolver melhor programas, projetos e ações de conscientização para cada município assistindo suas particularidades. Cada município se difere um do outro, pois os problemas enfrentados por cada um nunca são iguais. Nesse sentido, no campo da educação ambiental em tentar fugir do compromisso desenvolvimentista e aliar ao respeito das culturas tradicionais e a valorizar o compromisso individual, adota a expressão "sociedades sustentáveis", como pode verificar no documento "Tratado de Educação para Sociedades Sustentáveis e Responsabilidade Global, produzido na Conferência de 1992" (MORALES, 2012).

Diante disso, acredita ser importante tal reflexão diante dos sentidos dessas expressões tão utilizadas nos dias atuais, seja na gestão pública ou privada, sendo adotado, muitas vezes, como um modismo, sem que o conteúdo seja esclarecido ou compreendido.

\section{AÇÕES E POSSIBILIDADES PARA A PROMOÇÃO DASUSTENTABILIDADE}

A humanidade levou muito tempo até começar a se preocupar com os recursos naturais que os envolve. Demorou a notar, que com a criação de grandes cidades, com a 
construção de todo suporte para a população, e devido à industrialização e todas as alterações feitas ao meio ambiente, interrompendo seu ciclo natural e, aos poucos, foi podendo ser verificado que a qualidade de certos recursos como a água, o ar, o clima, o solo, os alimentos, enfim toda a natureza estava e continua sendo prejudicada (LEÃO, 2013).

Com a reflexão das práticas sociais, marcadas pela degradação do meio ambiente em que vivemos e do seu ecossistema, é necessário pensar e ir mais além. Começar a desenvolver algumas práticas com ênfase na sustentabilidade socioambiental, e refletir sobre práticas sustentáveis nos leva a compreender o que deve ser feito. Novos atores sociais como os administradores públicos que são os líderes das cidades, devem ser os principais mobilizadores e questionadores para a construção de práticas educativas e hábitos sustentáveis nas pessoas, ou melhor, em sua população em questão. Nesse sentido cabe destacar que a gestão pública tem principal importância para gerir processos que desenvolvam práticas na população. (JACOBI, 2003).

Segundo Oliva (2000, p. 02),

A discussão acerca da sustentabilidade das cidades se apresenta atualmente com uma das questões de maior relevância no Direto Ambiental, fundamental para vislumbrarmos um crescimento social sadio - não prejudicial às futuras gerações e, em contraposição aos caos que possivelmente instalar-se-ia caso nenhuma medida fosse tomada.

Uma cidade sustentável é aquela que é projetada ou transformada de modo que sejam considerados os impactos socioambientais, respeitando todos os padrões de consumo, dos recursos naturais, das gerações futuras e em consenso com todas as empresas e cidadãos (BRANDÃO et al., 2003).

Ainda segundo Brandão et al., (2003, p. 05), a principal tarefa dos administradores públicos, é de reorganizar o sistema de gestão, colocando esforços para buscar os conceitos em tornar uma cidade sustentável. "A dimensão ambiental deve ser incorporada às politicas setoriais urbanas (habitação, abastecimento, saneamento, ordenação do espaço urbano, entre outras)". Cada gestor de sua cidade, interligado sua administração deve priorizar um trabalho voltado para o desenvolvimento ambiental, levando isso por meio de ações, até sua população. 
Um dos municípios que vem desenvolvendo práticas sustentáveis é a cidade de Londrina no Estado do Paraná com uma população de mais de 500 mil habitantes. 0 projeto de reciclagem da cidade é feito de forma a estimular os cidadãos a realizarem de forma eficiente, mas também economizando na compra de alimentos, pelo projeto "Cesta verde", lançado em 2011, em parceira da Secretaria Municipal de Agricultura. O programa consiste na troca de lixo reciclável por alimentos orgânicos. Todas as sextas-feiras os bairros pré-estabelecidos recebem a equipe da prefeitura que era responsável por fazer a troca, assim também transmitindo o conceito de práticas sustentáveis, além de ações em forma de palestras nos bairros por meio de lideranças comunitárias no município. A cidade já recebeu prêmios nacionais e internacionais como o "selo catador" que é um prêmio que o Ministério do Meio Ambiente mostra o reconhecimento de locais com destaque na contribuição para o desenvolvimento sustentável e, ainda, o município de Londrina foi convidado a apresentar seu modelo de gestão na França (PORTAL BRASIL, 2011).

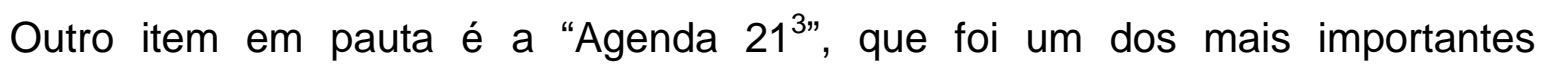
compromissos de ética sustentável firmado na conferência Rio- $92^{4}$, e que podemos destacar o desenvolvimento de cidades sustentáveis, mediante o plano de ação traçado de acordo com os problemas e prioridades de cada local ou região.

De acordo o Ministério do Meio Ambiente (BRASIL, 1999), foi desenvolvido um projeto chamado de A3P - Agenda Ambiental na Administração Pública, que consiste na adoção de novos referenciais na busca pela sustentabilidade socioambiental, no âmbito da gestão pública. O objetivo deste projeto é estimular gestores públicos a priorizar os princípios na gestão ambiental em seus mandatos, buscando a economia de recursos naturais e à redução de gastos institucionais por meio do uso racional dos bens públicos e da gestão adequada dos resíduos. O Ministério do Meio Ambiente beneficia com prêmios de destaque e reconhecimento os munícipios que conseguem atingir seus índices, fazendo com isso a ideia para outras cidades talvez desenvolverem. Para compreensão e

\footnotetext{
${ }^{3}$ A Agenda 21 é um conjunto de resoluções tomadas na ECO-92, que resultou em medidas para conciliar crescimento econômico e social com a preservação do meio ambiente. Foi organizada pela ONU.

${ }^{4}$ A Conferência das Nações Unidas sobre o Meio Ambiente e o Desenvolvimento (CNUMAD), conhecida como Rio-92, reuniu mais de 100 (cem) chefes de Estado. Foi importante pois, consagrou o conceito de desenvolvimento sustentável e conscientização de que os danos causados ao meio ambiente eram de responsabilidade os países desenvolvidos, e também que este países receberiam apoio tecnológico e financeiro para avançarem na direção do desenvolvimento sustentável.
} 
incitação, para que um município implante 0 projeto $A 3 P$ são necessários, 0 desenvolvimento e criação de alguns passos, como:

a) para criação e regulamentação o munícipio deve envolver ou criar cargos com servidores públicos de diferentes áreas para o acompanhamento de projetos e atividades voltadas para sustentabilidade;

b) identificação por meio de estudos dos pontos fracos e críticos, avaliando os impactos ambientais causados e os desperdícios gerados;

c) a partir da identificação, definir os projetos e atividades com a priorização dos casos a serem tratados com maior urgência, acertar recursos necessários tanto físicos como financeiros, acertando e colocando prazos;

d) implantação, envolver os colabores que foram definidos e todas as áreas de trabalho e a sociedade ou empresas em questão junto com os recursos necessários;

e) monitoração e avaliação, desenvolver um medidor de desempenho com base nas datas pré-definidas, e análise para verificação de falhas e possíveis melhorias;

f) estudo para melhorias, replanejamento se necessário, qualificação e treinamento buscando atualização do empenhados no processo, desenvolvimento de novas tecnologias e novas legislações.

g) avaliação total, levantamento de dados, identificação das metas atingidas, e reprocesso contínuo (BRASIL, 2013).

Projetos como o A3P são de suma importância por garantem ideias que foram testadas na prática e trouxeram resultados.

Outra possibilidade de repensar as práticas cotidianas são instrumentos de avaliação de impacto. Segundo Van Bellen (2004, p. 69), "os mais variados especialistas da área de meio ambiente afirmam que uma ferramenta de avaliação pode ajudar a transformar a preocupação com sustentabilidade em uma ação pública consistente". A ferramenta denominada Ecological Footprint Method, termo que em português remete a "Pegada Ecológica", corresponde a um indicador tanto analítico, quanto educacional, vendo que ela analisa não apenas a sustentabilidade das atividades humanas, mas também gera contribuição para consciência pública por meio dos problemas ambientais.

O conceito de pegada ecológica é baseado na ideia de que para cada item de material ou energia consumida, uma certa quantidade de área correspondente de terra produtiva e ecossistemas aquáticos são necessários para produzir os recursos utilizados e para assimilar os resíduos produzidos por dada população, 
sob determinado estilo de vida de uma dada população. Mostra a utilização de área de terra ou água como numerário de valor, mais do que apenas o capital financeiro (dinheiro). A pegada ecológica é portanto função do consumo de material e energia de uma população (VAN BELLEN apud ARRUDA, 2010, p.44)

Dentre a pegada ecológica, um dos componentes mensurados é o carbono, mais conhecido como Pegada do carbono, que conforme Brasil (2013) "mede o total das emissões de gases de efeito estuda causados diretamente e indiretamente por um indivíduo, organização, evento ou produto", contribuindo na analise quantitativa nos impactos causados, a partir do espaço físico e do consumo. Diante desses indicadores, também é possível determinar a pegada de uma determinada organização pública ou privada, industrial ou de serviços em funções dos fluxos de matéria e energia relacionados (VAN BELEN apud ARRUDA, 2010), o que pode ser uma ação e possibilidade para ser adotada na gestão pública.

No entanto, sabe-se que os desafios são grandes mediante ao interesse maior estar centrado na vertente do crescimento econômico, do que a articulação e interligação entre as dimensões social, ambiental e econômica, sem restringir outras variáveis. Mas, o repensar suas ações mediante os problemas localizados, já é um ponto de partida e que contribui com a continuidade da gestão pública.

\section{CONSIDERAÇÕES FINAIS}

A gestão pública é uma esfera de grande complexidade. Quando pensamos em um governo, devemos analisá-lo olhando como são difíceis os desafios a serem superados, porque a gestão pública não consegue apenas colocar em pauta apenas um enfoque. A priorização de certos conceitos, estes sim devem ser pautados, pois de antemão sem o desenvolvimento que leve em consideração a sustentabilidade, grandes prejuízos poderão se acarretar no futuro, não deixando talvez recursos para serem administrados.

Práticas de sustentabilidade nos municípios devem virar rotina numa gestão pública. Para tanto, atividades educacionais voltadas à questão socioambiental podem contribuir para as práticas dos cidadãos nos seus municípios. Talvez pessoas mais 
preparadas ocupando cargos públicos, poderiam criar estratégias adotadas para se buscar uma gestão mais voltada às práticas sustentáveis.

Os órgãos como a ONU, UNESCO em parceria com ministérios e com o governo tentam por meio de projetos e programas sensibilizar os gestores públicos da importância da sustentabilidade na administração. É de extrema importância que os municípios por meio dos seus gestores se inscrevam e participem, buscando certificações e reconhecimento, desta forma também provando a sociedade que se está conseguindo alcançar os objetivos e, para tanto, alguns indicadores de sustentabilidade podem ser adotados para proporcionar melhores caminhos a serem seguidos.

\section{REFERÊNCIAS}

ARRUDA, L. G. C. Valorização das Pegadas Ambientais: A Pegada Ecológica, a Pegada De Carbono e a Pegada D'água Como indicadores de consumo na perda de valor do ecossistema modificado pelo homem. Trabalho de Conclusão de Curso (Especialização em Sistemas Tecnológicos e Sustentabilidade Aplicados Ao Ambiente Construído da Escola de Arquitetura). UFMG, Belo Horizonte, 2010. Disponível em: <http://elegevalor.dominiotemporario.com/doc/ Valoriza.pdf>. Acesso em: 01 maio 2013.

BOFF, Leonardo. Sustentabilidade: o que é? E o que não é? Petrópolis, Rio de Janeiro: Vozes, 2012.

BRANDÃO, Antônio Carlos, et al. Agenda 21 e a sustentabilidade das cidades, 2003.

BRASIL. Ministério do Meio Ambiente. Agenda ambiental na administração pública A3P. MMA, 2013. Disponível em: http://www.mma.gov.br/component/k2/item/8852agenda-ambiental-na-administração-pública---a3p. Acesso em 16 de out. 2013.

BELLEN, Hans Michael Van. Desenvolvimento sustentável: uma descrição das principais ferramentas de avaliação. Ambiente \& Sociedade, v. 7, n. 1, p. 67-88, 2004. 
BOFF, Leonardo. Sustentabilidade: o que é? E o que não é? Petrópolis, Rio de Janeiro: Vozes, 2012.

CABRERA, Luiz Carlos. Afinal, o que é sustentabilidade? Disponível em: http://planetasustentavel.abril.com.br/noticia/desenvolvimento/conteudo_474382.shtml. Acesso em: 03 de out. 2013.

COUTINHO, Marcelo James Vasconcelos. Administração pública voltada para o cidadão: quadro teórico-conceitual. Revista do Serviço Público. Brasília, v. 51, n. 3, p. 40-72, 2000.

DOWBOR, Ladislau. Posfácio a gestão pública e sustentabilidade, ago. 2011 Disponível em:

https://www.google.com.br/url?sa=t\&rct=j\&q=\&esrc=s\&source=web\&cd=1\&sqi=2\&ved=0C DkQFjAA\&url=http\%3A\%2F\%2Fdowbor.org\%2Fblog\%2Fwpcontent\%2Fuploads\%2F2013\%2F01\%2F11Posf\%25C3\%25A1cio-Sampaio-aGest\%25C3\%25A3o-P\%25C3\%25BAblica-eSustentabilidade.doc\&ei=Ne5bUt_8J9ShqwGe5IC4Bw\&usg=AFQjCNHJVFuukDhR22ObF yM8I-2gllPDWg\&bvm=bv.53899372,d.eW0. Acesso em: 14 de out, 2013.

HOGAN, Daniel Joseph. Mobilidade populacional, sustentabilidade ambiental e vulnerabilidade social. Revista Brasileira de Estudos de População, v. 22, n. 2, p. 323338, 2005.

JACOBI, Pedro. Educação ambiental, cidadania e sustentabilidade. Cadernos de pesquisa, v. 118, n. 1, p. 189-205, 2003.

LEÃO, Marcelo Franco. A busca por hábitos sustentáveis na sociedade do consumo. Revista Científica ANAP Brasil, v. 6, n. 7, 2013.

LIMA, Paulo Daniel Barreto. Excelência em Gestão Pública. Rio de Janeiro:

Qualitymark, 2007. 
MORALES, Angélica Góis. A formação do profissional educador ambiental: reflexões, possibilidades e constatações. 2. ed. Ponta Grossa: UEPG, 2012.

MUNCK, Luciano; SOUZA, Rafael Borim de. Gestão por competências e sustentabilidade empresarial: em busca de um quadro de análise. Gestão e Sociedade, v. 3, n. 6, p. 254287, 2010.

NEVES, Arminda. Serviço público: para uma cultura de gestão na administração pública. 2002. Disponível em: http://dspace.uevora.pt/rdpc/bitstream/10174/2514/1/Recriar\%200\% 20Servi\%C3\%A70\%20P\%C3\%BAblico\%20Junho\%202001.pdf. Acesso em: 03 de out. 2013.

OLIVA, Liana Brandão de. A reinvenção das cidades como instrumento para o desenvolvimento sustentável. Revista do Curso de Direito da UNIFACS, n. 153, 2013. Disponível em: http://www.revistas.unifacs.br/index.php/redu/article/view/2489/1823. Acesso em: 10 out. 2013

PORTAL BRASIL. Cidades sustentáveis. Revista Brasilis, 2011. Disponível em: http://revista.brasil.gov.br/especiais/rio20/desenvolvimento-sustentavel/cidadessustentaveis. Acesso em: 16 de out. 2013

REZENDE, Denis Alcides; OLIVEIRA, Tatiana Souto Maior. A relevância da teoria NPM para contribuir com a sustentabilidade ambiental das cidades. Texto de apoio, 2004. 